\title{
Achegamento ao galego literario de Curros Enríquez
}

Elisardo López Varela

Universidade da Coruña

\section{Preliminares}

Deixábamos claro nun anterior traballo (López Varela 2000: 199-208) a respeito das ideas de Curros perante a lingua que este autor sempre se proclamou firme defensor da mesma, reivindicándoa alí onde tiña ocasión. Mais é de xustiza salientar que esta postura batía con grandes dificuldades sociais e lingüísticas pola situación en que se encontraba o idioma naquela época. Aínda así, Curros publicou a súa obra naquel galego que reflectía a fala da sociedade a que pertencía. A nosa intención é analisala pormenorizadamente nas páxinas que seguen, de tal maneira que, na medida do posíbel, poidamos comprobar o seu estado neses momentos e o grau de coñecimento que o autor posuía da mesma.

\section{Grafías e fonética}

O primeiro que chama a atención a un leitor de Manuel Curros Enríquez nas súas edicións orixinais' é o formato gráfico, multiforme e relativamente anárquico, en que se presenta a súa poesía. Mais ao analisarmos calquer obra literaria do século XIX ou de principios do XX descubrimos esta mesma situación, pois a ausencia dunha norma común e a intención de reflectir o máis exactamente posíbel a fala popular leva a que case todos os autores recorran ao emprego de moi diversos signos gráficos. Curros non foi alleo a esta situación, embora mantivese sempre unha certa fidelidade -con mínimas modificacións- a un mesmo sistema gráfico desde o seu primeiro poema, "Cántiga" (1869), até o derradeiro, “A Alborada de Veiga" (1907).

\footnotetext{
Ao longo deste traballo, os números que seguen a continuación das siglas (A, B, C=Aires da miña terra $, 1^{\mathrm{a}}, 2^{\mathrm{a}}$ e $3^{\mathrm{a}}$ ed.; $\mathrm{DS}=O$ divino sainete $; \mathrm{PS}=$ Poemas soltos) fan referencia á número de poema (ou Canto en $O$ divino sainete) seguido do(s) número(s) de verso(s), tomando sempre como referencia a edición da poesía de Curros de López Varela (1998). A sigla HG reférese á edición de El Heraldo Gallego ( $\mathrm{n}^{\circ} 10,11$ e 12 de 5, 10 e 20 de Marzo de 1877 respectivamente) en que apareceron publicados por primeira vez os tres poemas premiados no Certame poético de Ourense ("A Virxe do Cristal", "Unha voda en Einibó" e "O gueiteiro").
} 
Así, por exemplo, a utilización dos signos de admiración e interrogación non era uniforme, pois, sen nengún criterio aparente estabelecido, unhas veces aparecían ao principio e ao final da frase: ¿Quen se ri?, C 2.1071; ; Valente choromiqueira!, DS III.82; e outras, só ao final: Ouh Nazareno!, C 1.72; cántas bestas levóu?, C 16.9. Do mesmo xeito, a diérese, á parte de ser utilizada polo autor sobre os grupos $<$ güe> e < güi>, aparece tamén sobre calquer outra vogal, xeralmente por razóns métricas para marcar o hiato, co fin de indicar a contaxe de dúas sílabas: e röido d'a cubiza, C 33.58; non quixen oür máis nada, DS III.106.

Agora ben, se os exemplos anteriores mostran a existencia de anarquía gráfica, esta acrecéntase ao nos debruzarmos sobre a acentuación, que escapa, en liñas xerais, a toda norma fixa. Aínda que funcionaba un criterio xeral, tirado do español, achamos que as excepcións aparecen espalladas por toda a súa obra. Son frecuentes os casos de presenza ou ausencia do til nunha mesma palabra ou en palabras semellantes desde o ponto de vista acentual en contextos diferentes, feito que xera, ás veces, unha certa confusión e algunhas contradicións. E se o estudo o fixermos partindo das publicacións de poemas en revistas e xornais, a anarquía resultará máis ostensíbel.

Os tiles que Curros emprega son na súa grande maioría agudos, mais, ao seu lado, encontramos tamén dunha maneira esporádica os circunflexos (sôfre pena fonda..., C 2.46; dôno DS I.139; hante de pôr, PS 2.54) e, nalgún caso, nos poemas soltos -debido posibelmente ao editor- os graves: lévenno ò inferno, PS 2.46; cántigas quèr de galans, PS 5.4.

A respeito das palabras monosilábicas, non conseguimos achar unha norma fixa no noso autor para a acentuación de $a$, segundo se tratar dun artigo, unha preposición ou unha contracción $-a / a ́-$, e sobre todo a de $o(s)$, segundo for artigo ou contracción -o/ó-. Do mesmo xeito, outros monosílabos levan til sen motivo aparente: fírem' a sén, C 2.39; gráus e fariñas, C 2.144; y-a Roma vás, C 31.151.

Outras veces, encontramos acentos estraños por mor da aparición de crases fonéticas inusuais ou para distinguirmos formas verbais doutras voces homógrafas: que trás contigo C 2.356; tu rósnos como os vermes a fror do laranxeiro, C 2.357; que olladas lle botan él, C 3.152; que cousas me hoxe sán, C 16.40.

As oxítonas polisílabas acabadas en -ón, -án non levan en moitos casos til, feito frecuente na época (o mesmo fixo Rosalía e da mesma maneira aparecen exemplos na Gramática de Saco Arce): que de soliman che sirvan, C 2.152; outon, C 21.16. Non obstante: o vento que d'o roncón, C 4.92; d'a gallega emigración, C 4.95. A confusión é tan grande que a mesma palabra pode aparecer con ou sen til nun poema a escasa distancia unha da outra: unha procesion, DS I.54 vs. d'a procesión, DS I.58. O mesmo sucede cos acabados en -en, -in, -un: outro non hay segun 
contas, C 2.84; y-os cunvidados tamen, C 3.144; ninguén, C 28.13; repitin, C 29.32; latín, C 31.92. Por outra parte, é frecuente no autor-como noutros escritores contemporáneos seus-, a acentuación das palabras oxítonas rematadas en ditongo decrecente: espallóu, C 5.12; cinguíu, C 17.2; morréu, C 32.1.

Nas paroxítonas a confusión tamén é a nota dominante. Existen palabras con distribución anárquica de tiles que non seguen nengunha norma: nóivos, C 2.182; o meu cólo, C 7.52; ántes de ter, C 21.138; saludáina, C 26.4; o mesmo acontece cos demostrativos (dése libro, C 33.44; ése lobo que t'arrasa, C 33.76 vs. eses nomes, C 33.115) e cos pronomes persoais (éles y-élas, C 3.179 vs. un chau que n'é d'eles, C 15.118). Ademais, rexístranse acentos que marcan a contracción da preposición a coa vogal inicial dos demostrativos este e ese e mais co pronome el e o indefinido outro: volvendo áutro lado, C 15.67; preso ónha argola, C 15.87; ¿qu'é sinon responder ésas perguntas...?, C 1.19; e salva ésta probe nai, C 21.147; ¿qué lle ofrecedes na nativa terra / ése que a cruzar vai mares de fel?, C 25.42.

Nas proparoxítonas a acentuación resulta moito máis regular, pois a utilización do til é xeral: árcades, C, 1.2; últemo amor d'o páledo Macías, C 1.63. Porén, nalgunhas ocasións, aparecen palabras que non o levan (comaros e corgas, C 26.2; lengoa, C 27.21), chegando inclusive á alternancia no mesmo poema: patrea, C 31.6 vs. pátrea, C 31.137 .

O apóstrofo, indicador da supresión da vogal final dunha palabra anterior a outra que comeza tamén por vogal, úsao Curros, como practicamente todos os seus escritores contemporáneos, dunha maneira constante e frecuente. Saco Arce (1868: 143-144) recollía xa os seus principais usos. Segundo o gramático ourensán, os pronomes enclíticos, os adverbios, as preposicións e as conxuncións eran as partes da oración que máis comunmente sofrían a perda da vogal, en canto que o verbo non soía experimentar esta elisión, salvo nos casos en que ía seguido dun pronome persoal. E acrecenta:

Con el nombre es todavía menos comun el apóstrofo, no verificándose apenas, sino con la $e$, ó cuando las dos vocales encontradas son una misma repetida [...]. El apóstrofo aunque frecuentísimo, no es sin embargo forzoso, excepto con la preposición de y con los afijos me, che, lle, seguidos del pronombre-artículo $o, a$.

Todos estes usos aparecen en Curros. O poeta celanovés utiliza este signo gráfico sistemática e regularmente cando quer marcar a contracción das preposicións de e en co artigo, co demostrativo, cos indefinidos un, algún, outro e cos pronomes persoais el, ela: n'unha lengua conecida, C 1.17; d'a côr d'a sangue, C 1.51; un bico tras d'unha cea, DS 0.57; n'as boquëadas d'a morte, DS 0.60; d'os patrios eidos, PS 17.40. Porén, existen casos en que non aparece (cal coiro no lume, C 27.9; nesa fontiña, HG 1.1; no longo das tuas pestanas, HG 1.8) ou aparece desprazado: 
de cada nota de'la, C 28.9. Ás veces vémolo en posicións inxustificábeis: que d'eica q'os namorados, C 2.187; cibdá que por'sobr'os mares, C 13.5.

Mais o o poeta modificou os seus usos ao longo da súa vida. Por exemplo, na edición de "A Virxe do Cristal" aparecida en El Heraldo Gallego, as contraccións realizadas coa preposición en aparecen con hifen, e non con apóstrofo, para cambiar de criterio nas edicións seguintes: vermes envoltos n-o monton aceso, $\mathrm{HG}$ 2.7; pódia ser, ben n-a vila, ben n-aldea, $\mathrm{HG} 2.55$. O mesmo sucedeu con todal'as, HG 2.187 e todal-as, C 2.187. Como exemplo de redución de apóstrofos nas edicións de Aires a respeito da edición de El Heraldo Gallego podemos citar os versos 192 e 300 da citada composición: déndesd'a vil'hastr'aldea, HG 2.192 e déndesd'a vila hastr'a aldea, C 2.192; d'end'huxe n'hay nada, HG 2.300; dend'hoxe n'hay nada, C 2.300.

Na realidade, a utilización do hifen tamén se converte nunha constante. O seu uso chega á separación do verbo do pronome persoal átono enclítico: Rosiña tomába-o á risa, C 2.172; moito q'agora vale máis calál-o, C, 2.458; pasándo-o, C 29.12; síntoo, C 32.6; fíxo-o falar DS III.62. Por outra banda, é sistemática a súa utilización coa conxunción copulativa $y$ seguida de palabra que comeza por vogal e cando aparece formando ditongo coa vogal seguinte: y-escribir, $\mathrm{C} 0.17$; y-o voso morto fede, $\mathrm{C}$ 32.40; y-é que n'este tempo, DS 0.61. Mais: y en tanto n'aldea, C 15.131.

Aparece tamén o trazo para marcar certos casos de alveolaridade de $n$, basicamente co adverbio de negación non seguido do pronome persoal átono: non-o nego, C 21.140; non-a crebés, C 23.41; non-o axo, C 25.9. Así mesmo, utilízao para indicar o alomorfo -lo do artigo: todal-as noites, C 3.9; por vel-o mar, C 21.42; entrambolos remos, C 29.65; pol-o camiño, DS I.78. Inclusive en casos non habituais: outrolo seu negocio, C 2.447; doentel-os deixo, C 29.35; érmol-os seus saídos, C 35.1. Mais ¿seralo demo?, C 2.574.

Por outra parte, en liña co galego decimonónico, cómpre salientar a utilización de $<y>$ en concorrencia con $<\mathrm{i}>$ en certas posicións. Mais a vacilación é constante ao longo da obra currosiana. Nunha carta ao seu editor Martínez Salazar, con motivo da publicación de $O$ divino sainete, recoméndalle que substitúa $<\mathrm{y}>$ por $<\mathrm{i}>$ ao final dalgúns vocábulos². Así sucedeu, por exemplo, no verso 21 do canto VI: no

2 Hai cartas do poeta onde se espraia sobre ortografía do galego: acerta na súa clasificación (hoxe matizada) en dous grandes dialectos; sostén a falsa idea dunha colonización grega da Galiza e defende a convivencia entre $<\mathrm{i}\rangle$ e $\langle\mathrm{y}\rangle$, aínda que para $O$ divino sainete (1888), que tamén publicou (fóra da "Biblioteca Gallega") Martínez Salazar, advirte ao editor: "Si ve Vd. las primeras pruebas, cuide de sustituir la y griega en el final de algunos vocablos (yo taché algunas pero no todas) poniendo en su lugar la i latina", o que contrasta con aquela anterior defensa: "Yo difiero de Saco únicamente en que no acepto como él en absoluto el empleo de la i latina, sino que la circunscribo á aquellos casos en que suena como vocal. Al final de vocablo, su empleo me parece herético" (véxase Martínez-Morás Soria 1987: 22-24). 
manuscrito autógrafo figura escramey saudando os osos e na $1^{\text {a }}$ edición (1888) aparece escraméi saudando os osos. Porén, en Aires da miña terra e nos poemas soltos aparece $<\mathrm{y}\rangle$ case sistematicamente en posición final absoluta (palabras acabadas en ditongo decrecente): dispoñey, dispoñeivos pr'a seitura, C 20.25; ceibay novas ideas, C 20.29 vs. vai bôa, C 3.246; como conxunción copulativa seguida dunha vogal: $y$-o voso morto fede, $32.40 ; y$-a través d'unha vidreira; DS, III.4; como vogal epentética ou antihiática: lev'á un lado d'o chapeyo, C 3.95; cayéu n'a praya, DS III.154; en posición intervocálica: e trayo, C 9.7; co'as sayas, HG 1.6.

Canto a outras grafías, débese, en primeiro lugar, asinalar as contradicións do poeta verbo da presenza e/ou ausencia de $<\mathrm{h}>$, seguindo, en xeral, un criterio etimolóxico, por ser un bon coñecedor da lingua latina. Mais, de todos os xeitos, rexistramos casos antietimolóxicos, tanto por ausencia (ortas, C 2.160 vs. hortas, C 33.33; oxe, C 6.11; órreos sin grau, DS VIII.38; óspedes, PS 10.67; armunía, C 3.207, armonías, C 30.23), como por presenza, neste caso por máis que probábel influencia do español: hórfos, C 2.173; henchen, 15.182; hombros, C 20.24, hermida, DS VIII.50; os hósos son d'ela, PS 7.13; hirmanciños, PS 3.184.

Para alén de certas vacilacións na representación da fricativa interdental xorda (perguizeiro, C 2.443; berze, C 8.14, frente a berce, C 8.10), moziños, C 10.19, e mociños, C 26.3; cazique, C 31.82; de bruzes, DS VII.119), a distribución de <b> e $\langle\mathrm{v}\rangle$ segue, en xeral, un criterio etimolóxico, aínda que aparecen algúns casos estraños: travallache, C 33.62; crabado, C 2.1064; unha cobiña, DS VIII.207. Ademais, pobo figura maioritariamente como povo.

Finalmente, outras grafías ocasionais parecen suxerir a idea de que Curros, como algúns autores contemporáneos, incorporou esporadicamente grafías medievais -ou portuguesas na altura- para a fricativa palatal xorda: viajeiros, PS 10.71; d'as almas virges, PS 3.162 .

Se no apartado gráfico as solucións son -como xa vimos-moi variadas e diversas, a análise de certos aspectos que fan referencia ao ámbito fonético confirma esa mesma tónica de variabilidade e diversidade acordes co momento histórico de recuperación da lingua nun contexto diglósico e conflitivo.

Deste xeito, o vocalismo tónico mostra unha maior estabilidade do que o átono, resultando menos vulnerábel ás alteracións de timbre, xa que só esporadicamente agroman algúns casos de mudanza vocálica especialmente chamativos, sobre todo as formas imperativas respunde, que aparece nas catro edicións en vida do autor (C 2.232) e irgue (PS 2.17) e mais o adverbio uxe (moito madrugas uxe, C 2.439),

\footnotetext{
Neste caso huxe aparece en rima con forruxe. Por outro lado, este cambio do timbre afectou as tres edicións do libro de Aires (A, B, C), pois a edición de El Heraldo Gallego tiña primitivamente a forma hoxe. Curros fixo despois a modificación, sen dúbida, por observar este defecto na rima.
} 
ambas de base dialectal (Ferreiro 1999: 36 e 43). Noutras ocasións a vacilación está presente na conxugación de formas verbais con falsa alternancia vocálica: nada Martiño destengue, C $2.1144 ;$ n'o teu cólo dorma, C 9.59.

Ademais, tamén en liña co galego literario do século XIX, a poesía de Curros mostra numerosas vacilacións no vocalismo átono, tanto en posición pretónica como postónica, afectando fundamentalmente as vogais palatais $e / i$ e as velares $o / u$. Como dado significativo, debemos destacar a existencia dun grande número de palabras que apresentan fechazón vocálica nos poemas publicados por El Heraldo Gallego premiados en 1877 ("A Virxe do Cristal", "Unha voda en Einibó" e "O gueiteiro"), e que despois foron modificados polo proprio autor repondo o timbre xeral. A modo de exemplo citamos os seguintes: anamorado, C 2.1116; sacreta, C 4.87; Portogal, C 16.54; páteos, C 35.8; cólara, DS IV.3.

Tanto no vocalismo como no consonantismo son frecuentes os casos de asimilación e disimilación de fonemas segundo podemos comprobar en casos como San Benito quirido, C 29.22; condenara o condanado, C 33.83.

Variación preséntaa tamén a preposición entre, cuxa tonicidade secundaria leva a que a primeira vogal vacile no timbre, facendo que topemos casos de antre: entr'edras, C 2.78 vs. por antr'aquel xentío, PS 3.83 .

Ademais, neste mesmo ámbito do vocalismo átono, podemos asinalar a presenza de síncopes (podroso, C 36.42), de próteses (asuspiróu, C 2.1168), de epénteses (chapeyo, C 3.95) e de parágoxes (nunca outra tal se ha de vere, DS 0.43), fenómenos proprios da lingua popular, que, máis unha vez, eran recollidos habitualmente no galego literario decimonónico.

Nesta mesma liña aparecen outros fenómenos que afectan o consonantismo, como a metátese de $<\mathrm{r}>$, que aparece en múltiplas ocasións na obra do poeta de Celanova, tanto con mudanza de posición, quer na mesma sílaba (oférceno, C 29.6; pirmores, C 31.41; persentóuse, DS II.75), quer en diferente sílaba (os probes, C 2.145; esquirbir, DS VII.53; pedricando, DS VIII.170), como tamén con intercambio no grupo $<\mathrm{rl}>$ (bulrona, C 2.1066).

Dentro do consonantismo adquire especial relevancia o estudo do seseo. O feito de Curros ser natural de Celanova, na provincia de Ourense, onde as isoglosas do seseo, tanto implosivo como explosivo, non alcanzan esta vila (Fernández Rei 1991: 54-56), fan supor un Curros non seseante, mais con dous factores que poden incidir nesta adscrición dialectal do poeta: seu pai procedía de Santiso (Melide), localidade en que o seseo implosivo estaba arraigado, e, por outra banda, Curros coñecía perfeitamente a obra doutros escritores seseantes como Rosalía. Como acontece noutros casos, máis unha vez o poeta móstrase vacilante na 
representación gráfica deste fenómeno. Aparece con frecuencia en monosílabos ( $a$ nosa vos C 1.5; arredor d'unha lus C 2.0.4; s'algunha ves o faguía, C 2.136; fixeron á crus n'os pratos, C 3.145; tal ves, C 25.30), mais tamén o achamos en palabras polisílabas: Xan de Ventraces y-o infelís Martiño, C 2.523; ollo sin párpado, atrós, C 2.656; infelís amador, C 11.17; iste cális esmaltado, DS VIII.46. Ao lado de todas estas formas, existen outras en que non se manifesta: o monosílabo paz mantén a grafía $<\mathrm{z}>$ en todas as ocasións: é de xente de paz, $\mathrm{C}$ 2.18; querías paz, DS II.24; mais non é o único: y-a luz, C 26.16; de dez Perlados, C 35.22; y-a voz tornóu; DS I.43; pois diz que foi levantado, C 2.85. Os casos de seseo que no noso autor se rexistran son todos implosivos, excepción feita de dous, lisencia, C 3.56, PS 3.89, e cubisa, DS II.79, o primeiro producido por unha disimilación consonántica e o segundo por cuestións rimáticas, pois cubisa rima con misa.

\section{Morfosintaxe}

Desde unha perspectiva morfosintáctica, son numerosas as cuestións lingüísticas dignas de comentario. En primeiro lugar, débese salientar o comportamento do poeta con relación ao tratamento dado ao artigo canto á distribución dos seus alomorfos. A forma asimilada -lo aparece sistematicamente coa preposición por, case sempre con hifen; pol-a tarde, C 13.15. Con tras e con máis tamén aparece o mesmo alomorfo: que tral'último queixido, C 2.29; a touza e máil-a silveira, DS V.9. E o mesmo acontece con todos: todol-os rios, C 1.25; de todal-as razas, DS VIII. $108^{4}$.

Mais, por outra parte, a constante alternancia no uso das dúas posibilidades gráficas do artigo con formas verbais acabadas en $-s$ ou $-r$ impede estabelecer unha norma de uso válida: veu ver a labranza, C 2.270; curas as feridas, C 9.10; fomos ver as galarías, DS VIII.5; que baixes os ollos, $\mathrm{HG} 1.5$; deixar as patrias ribeiras, PS 14.135; non queren collel-a chaira, C 2.860; érguel-a cabeza, C 13.6; comenzámol-a xornada, DS I.163. A forma asimilada do artigo está presente, así mesmo, en contextos que, sendo frecuentes na lingua oral, son rexeitados habitualmente na representación escrita; isto é, a asimilación do artigo cando vai precedido de participios, substantivos ou algúns pronomes: que batan millol-a sola, C 2.116; outrol-o seu negocio, C 2.447; Dio-lo queira, C 3.79; murchol-os dous, DS V.1; tres vecel-a afiéy, PS 6.1; tendidal-as velas, PS 10.37; arregañádolos dentes, PS 11.81 .

\footnotetext{
O que si tamén aparecen, por causas métricas, son as reducións silábicas en tod'os trebexos, C 2.773, ou envexa de tod'as mozas, C 3.31, formas tamén documentadas noutros autores decimonónicos, como Pondal. Tamén é digno de mención un caso inhabitual de asimilación de todo, en singular, co artigo, seguramente por analoxía co plural: todiñol-o perden, C 15.126.
} 
Canto ao xénero, Curros Enríquez non foi alleo á situación de conflito lingüístico xeneralizado, e na súa obra mostra numerosas vacilacións no tratamento xenérico de diversos substantivos. Así, o substantivo cárcere, documentado unha única vez na súa forma galega sen marca de xénero (en cárcere de súa Nai, C 2.684), convive co castelanismo cárcel, feminino: n'a cárcel d'o Vaticano, DS VIII.135. A voz costume aparece en tres casos co xénero marcado; en dous deles mantén o patrimonial (d'os nosos costumes, PS 10.81; os sans e bos costumes, PS 18.13), frente a e por gallega costume, C 2.401. No substantivo cume predomina o seu uso en masculino ${ }^{5}$ (ten n'o cume un penedo, C 29.2; d'os altos cumes, DS V.10; N'o cume d'o Medulio, PS 19.21), mais ao seu lado descubrimos dous casos en que utiliza o feminino (n'as lívidas cumes, C 14.38; os ríos y-as cumes, PS 10.83), o mesmo que con dote, mel e sinal: Fay falla / tér dote: o señor Abade / d'aprontarma deu palabra, C 2.1039-1040; ¿Dote? Ti non a precisas, C 2.1041; de purrela com'a mel, C 3.142; sin xiquera unha sinal, C 2.652. E coa voz sangue as vacilacións son claras, pois encontramos os mesmos casos de masculino que de feminino: coa sangue lixado, C 12.27; d'a satúrnea sangue, C 28.11. No entanto, outras veces mantén o xénero patrimonial: o sangue d'as venas, C 15.115; o teu sangue vertido, DS IV.125.

Dun modo semellante se comporta Curros con certos nomes con xénero feminino patrimonial. Así, a voz propria árbore non a topamos na obra do autor, mais álbores, sempre en masculino e, nunha ocasión, árbol: os álbores espidos, C 5.25; n'os álbores brúa, C 14.39; árbol será de paz, C 7.45. Tamén aparece o castelanismo morfolóxico en arte (ó arte, C 31.154; a cencia e o arte, DS IV.141; si $o$ arte perseguirdes, PS 3.195), mentres que calor ofrece vacilación no xénero; en dous casos aparece en masculino: ó calor d'amortecida lume, C 16.17; o calor meciñal do teu bafo, C 29.58; e só nunha ocasión mantén o feminino: que a calor derretería, C 2.666. A mesma alternancia vémola co vocábulo lume (o lume sin cardes, C 25.18; cal coiro n'o lume C 27.9 vs. ó calor d'amortecida lume, C 16.17; a lume morta, C 16.47), así como nos substantivos cor; dor e orixe: de côr máis louro, C 2.674; a cor, DS IV.89; cánto delor, C 2.748; pr'os meus doores, C 9.16; eses doores, C 33.86; eterna dôr, DS V.24; do seu dolor, PS 11.28; de orixe divino, C 2.925 .

Finalmente, os nomes rematados no sufixo -axe apresentan tal vacilación xenérica que resulta difícil emitir unha regra xeral. Hainos que manteñen o xénero patrimonial (a romaxe, a camaradaxe), mais outros, por influencia do español, aparecen como masculinos (o lenguaxe, un viaxe, o paisaxe): como me amostra o

A palabra cima mantén o xénero feminino, mais resulta estraño en Curros a presenza dun caso en masculino (n'o cima d'a torre, C 35.15), que pode deberse a unha gralla. 
traxe, C 2.804; do prácido follaxe, C 5.30; n'aquil paisaxe invernizo, DS V.18; tanto por todo o viaxe, DS VII.44; seguindo á pós d'a romaxe, DS VII.85; y-en boa camaradaxe, DS VII.87; e un ultraxe en cada boca, DS VIII.126.

Algo semellante ao que acontece co xénero podemos velo na formación do plural, en que, de novo como outros autores coetáneos, aparecen solucións diverxentes. En primeiro lugar, nas palabras que acaban en vogal, o acrecentamento de /s/ é norma xeral: mapolas y-alelís, C 2.344; y-as eixadas, C 30.22. Isto sucede inclusive en vocábulos como rei e lei, con formas plurais hipercaracterizadas na fala popular: de reis é tiranos, C 29.44; as leis municipales, C 32.37. Mais: qu'envidian os reises, C 15.46. Á parte destes casos, a presenza da solución española maniféstase algunhas veces: os calados ayes, C 7.31; d'albos tisúes, DS VII.128.

En segundo lugar, nos vocábulos acabados en consoante - $n$ Curros foi, en xeral, bastante fiel á norma do seu territorio lingüístico, correspondente á solución do bloque central, ao desaparecer a nasalidade medieval produto da caída de $-\mathrm{N}$ intervocálico latino e tomar o alomorfo /s/: os bailarís, C 3.232; os desdés, C 11.4; fillos ningús, C 21.87; en montós xigantes, DS VIII.13; dous lacós, PS 19.32. Mais outras veces, aínda que en menor medida, o autor recorre á solución propria do bloque occidental: cáns, C 14.20; rans, DS III.54; bens, DS VIII.61; querubins, PS 3.161; galans, PS 5.4. Estas vacilacións poden ser debidas á proximidade da isoglosa da área lingüística occidental, ou, máis probábel, á influencia doutros escritores.

En terceiro lugar, a solución máis estendida das palabras acabadas en - $l$ é a adxunción do alomorfo -es, mais tamén con presenza doutras solucións. Así, os monosílabos forman o plural acrecentando este alomorfo -es: peles, C 15.48; tales contos, C 21.46; vales, C 26.2; soles, DS 1.71; mais ocasionalmente vemos casos como os sete vis escudos, C 23.15. Algo semellante acontece coas voces paroxítonas: furar tuneles, C 15.90; por xustos os débles, C 15.156; ánxeles, C 36.20; mais achamos o caso seguinte: y-os ollos baixos e inmovis, DS IV.79.

Por outra parte, as polisílabas oxítonas acabadas en -al acrecentan tamén o alomorfo -es: piñeirales, C 2.65; catedrales, C 31.33; as leis municipales, C 32.37; libres areales, C 36.1; imortales, C 36.3; os seus ideales, DS III.59. Mais tamén o hiato resultante da perda de - $l$ - intervocálico latino se resolve cunha asimilación das dúas vogais a favor da primeira, que posteriormente acabaría contraendo nunha única (solución típica do bloque central): os maternás doores, C 7.28; os arsenás, DS VIII.119; inmortás, PS 3.196, solución que non era allea, por exemplo, á propria Rosalía, que apresentaba este tipo de resultados (mortás). Nunha ocasión o hiato resultante da perda do $-l$ - converteuse nun ditongo, solución propria do 
galego oriental: ladrais, PS10.58 $8^{6}$. As palabras acabadas en -el engaden o alomorfo -es: caraveles, C 2.73; os verxeles, C 15.12; lebreles, C 15.124; y-os cinceles, PS 11.45. Outras veces a solución é a do bloque central: con catro mantés ${ }^{7}$ cuberta, C 3.129; rosas é cravés, C 25.54; en papés de duas coores, PS $14.55^{8}$. Finalmente, os substantivos acabados en -ol e en -il apresentan a solución -es (rousinoles, DS III.104), en canto que nos terminados en -il conviven a solución castelanizada e a autóctona: seis perniles, C 29.30; volvoretas xentís, C 2.3; os cadrís, C 3.220; fusís, DS IV.71; ninfas xentis, PS 10.62.

Para finalizarmos este apartado dedicado ao nome ${ }^{9}$, coidamos de interese a análise da solución currosiana para os sufixos latinos -ANU/-A, en que a solución maioritaria do poeta é a propria da zona en que naceu, a do galego do bloque

6 Carballo Calero (1972: 26) detense a observar este tipo de plurais afirmando: "En Curros los plurales de tipo genuino cuartés, arsenás, cardenás, son proporcionalmente más frecuentes, al menos a partir de $O$ divino sainete (1888). Pero, por otra parte, Curros desconoce los plurales más arcaicos mortáis, matináis. Es decir, que la lengua de Rosalía refleja en este aspecto las huellas de una situación más arcaica que la lengua de Curros; pero presenta al mismo tiempo una más rápida y completa castellanización. El gallego suroccidental resulta más arcaico que el central en sus formas autóctonas; pero ha sufrido más, por otra parte, la erosión de la lengua oficial: el proceso de castellanización ha avanzado más en este punto".

7 Respeito ao caso de mantés, debemos manifestar que se encontra a forma singular manté (con catro mantés cuberta / por que non chega un manté, C 3.129-130). Noutros autores achamos esa forma plural como singular, que, como indica Freixeiro Mato (1993: 90), só se pode explicar a partir do plural centro-occidental mantés, que xerou posteriormente a forma manteses, derivando dela un singular analóxico mantés.

8 Hai un caso dubidoso: trátase da solución que Curros dá ao plural do substantivo nivel que aparece no verso 34 do poema "Na apertura do Centro Gallego". A leitura podémola facer de dúas maneiras: nivéis ou nivéls. Nas edicións de El Regional (Lugo, 1.4.1893) e El Eco de Galicia (Habana, 22.4.1893), rexístrase nivéls, en canto que na edición de El Globo (Madrid, 28.3.1893) a distinción é máis complexa. A solución nivéis, propria do bloque oriental, repítea Curros nunha soa ocasión que apontamos arriba (ladrais); a solución nivéls (pola que nós optamos), dáse noutros autores da época, como Rosalía, que en Cantares Gallegos utiliza en varias ocasións este tipo de plurais: frols, mals, mortals, nabals, sutils.

9 Centrándomonos estritamente no adxectivo, son merecentes de comentario a alternancia bon/bo, en que o poeta opta por alternar ambas as solucións, cunha maior utilización da primeira, de que contabilizamos 16 casos por 4 da segunda. Este feito contrasta en boa maneira coa distribución xeográfica de ambas as formas, pois o autor pertence a unha área en que prevalece a solución bo: bon samaritano, C 26.29; meu bon amigo, C 31.169; bon labrego, C 33.1; ;Bon peixe!, DS III.153; un bon gaiteiro, PS 3.30; etc. Polo contrario, aparece bo en: bó castigo me deches, C 2.1005; a noite á bó andar caía, DS V.4; bo consello, PS 14.177.

Neste mesmo ámbito adxectival cómpre salientar a utilización da forma comparativa millor (qu'éo meu médeco millor, C 21.63 ; non agarde millor sorte, PS 11.115; y-o millor Dios o diñeiro, PS 14.32), a preferencia pola forma peor frente a pior (piores q'a rabia, HG 2.298 / peores q'a rabia, A, B, C 2.298; do peorciño DS II.143), así como a alternancia maor/mor, sendo inexistente a forma maior: cando n'as festas maores, C 4.41; os ósos d'os teus maores, DS IV.116; collían roxo inda mór, C 3.74; que no mundo a mor riqueza, C 33.106. 
central, -au/-á: n'a miña mau, C 2.787; como de vrau regalada, C 2.834; hirmauciños, C 2.875; nin gráu pr'a semente, C 15.130; y-as maus, C 23.21; o chau, DS VIII.124; meus hirmaus, PS 10.1. Mais non sempre sucede así, pois apresenta casos, non habituais do galego central, en -an, aínda que todos os recollidos pertencen aos poemas soltos que son -como dixemos- menos fiábeis: d'o céltico chan, PS 10.45; hirmans, PS 14.232; man, PS 17.58. No feminino, o resultado xeral de -ANA latino é -á, mais a isoglosa de separación con -án pasa tan próxima a Celanova que a solución do noso autor apresenta alternancia. A isto debemos sumar a solución culta -ana e algún castelanismo: unha muradana, C 2.405; xentes cortesanas, C 2.918; baix'a ventana, C 2.968; d'a mañan, C 5.20; a alta campana, C 12.17; certa clás de mazá, C 21.28; vai por lan á Roma, DS I.149; á esas rans d'a democracia, DS III.54.

No apartado referente aos pronomes deterémonos naqueles aspectos máis salientábeis, especialmente no pronome persoal, en que debemos facer constar a alternancia de $t i / t u$ como forma de suxeito, con preferencia para a primeira das formas: ti quéresme moito, C 2.261; tí apareciche enton, C 34.9; tí, meu coitado San Bode; DS I.112. Mais como corresponde a unha zona xeográfica en que o uso común na fala é o de $t u$, tamén vemos casos en que aparece a forma etimolóxica: 'tú rósnos C 2.357; rabearas tú, C 2.772. Na edición de "A Virxe do Cristal" en El Heraldo Gallego, ao lado de $t i$ achamos $t u$ con moita frecuencia: tu quéresme moito, HG 2.261; tu seique tes gana, HG 2.288. Esta alternancia solucionaríaa na $1^{\text {a }}$ edición de Aires a favor da forma $t i$, o que demostra unha escolla lingüística consciente na dirección do estándar moderno da lingua.

Por outra parte, no que di respeito á forma do pronome de terceira persoa $\mathrm{el} / \mathrm{il}$, a situación é semellante á anterior, xa que predomina a forma común, aínda que tamén existe a solución il por ser a típica desta zona ourensá: il corre, C 1.191; pensaba n'íl, C 2.736. En HG tamén aparece o dialectal il (il era un mozo arrogante, HG 1.167), correxido en Aires d'a miña terra. Ademais, achamos a forma invariábel $e l$, substituto do antigo pronome elo (¿Él é certo?, DS II.1), que, situado no inicio da curva de entoación, está tomado como reforzo interrogativo á maneira de acaso, entón, $\log o^{10}$.

Canto á distinción das formas de dativo de $3^{\mathrm{a}}$ persoa (lle/lles), tamén en Curros se percebe a neutralización, dentro dunha tónica de diferenciación entre singular e plural: fálalle ós emigrados, PS 8.17; os homes non lle fan caso, PS 11.29; a todos lles gusta, C 2.963; tando d'esto se lles dá, C 3.40.

Outras cuestións de interese fan referencia á alta percentaxe de utilizacións das formas do pronome de solidariedade (ipois estouche servido!, C 2.474; que che se

10 Sobre o particular, véxase Álvarez / Regueira / Monteaguado (1986: 169). 
rin de ti, C 2.564; eu ch'o topey, eu ch'o tiven, C 2.1021; nadia ch'é rico, C 16.13; pois non ch'hay can que ch'a roa, C 21.11; sonche os verdadeiros santos, DS II.123; que mala loba che me non xante, PS 2.11; y-eu non vos toco nada, PS 3.19; evos a lengoa gallega, PS 5.1), así como todo aquilo que fai referencia á colocación das formas átonas do pronome persoal. As veces que modificou a posición canónica dun clítico foi, na maioría dos casos, por razóns enfáticas ou métricas: x'estóuvos' ascoitar, C 2.808; “'Qué tempos!” me dice, C 12.56; Vostedes me sean testigos, C 21.114; se ás boas non veste, PS 2.60; a cencia o pregoa y-a cencia non mente, PS 10.21; Penélope o diga, PS 10.51; pr'a cando él trunfe eu lla gardo, PS 17.110. Do mesmo xeito, manexa extraordinariamente ben a interpolación, recurso tradicional e enriquecedor do idioma, especialmente frecuente co adverbio de negación non: pra que se lle non coneza, C 2.316; dende que te non vexo, C 2.999; non hay quen lle non deba consolos e favor, C 2.1187; pátria que os non mantén, C 25.48; ¿quén te non maltratóu?, C 31.126; que mala loba che me non xante, PS 2.11. Outras veces, a interpolación dáse cando o suxeito se sitúa inmediatamente antes do verbo, desprazando deste xeito o pronome átono para unha posición anterior: Si probas m'él pidira e darllas eu pudese, C 2.371; antes de se o sol deitar, PS 14.168.

As formas dos demostrativos corresponden en xeral ao sistema maioritario con ['e] tónico, a pesar de que a zona xeográfica de procedencia de Curros responde máis a un paradigma con hipercaracterización nas formas masculinas con vogal tónica ['i], que é característico da maior parte da provincia de Ourense (Fernández Rei 1991: 69-73). Eis algúns casos: este libro, C 1.29; ese idioma, C 1.41; por aquel bosque, DS V.152; n'esta noite, DS I.11; estas páxinas, C 1.32; esa fala pulida, C 1.37; aquela virtú, C 2.374; d'a xente aquela, DS III.133; y-esto dito, DS I.127; pra vivir bástache eso, C 31.142 vs. d'iste ano, PS 2.9; ises compatriotas nosos, DS II.118; irgue isas pontes, cega ises baches, PS 2.17; n'aquil celaxe promizo, DS V.16; mirando aquiles horrores, DIVI III.163.

Por outra parte, e como acontece, por exemplo, na obra pondaliana, en Curros pode aparecer o pronome posesivo sen o artigo, normalmente por razóns métricas: morreu voso realismo, C 32.32; teu millor libro, C 33.94; seus rezos, DS IV.73; onde vosas obrigas, PS 3.3; miña alma toda, PS 3.91; seus sacretos, PS 3.132; noso chau paterno, PS 3.140; tray meus versos, PS 14.80.

Canto ao indefinido, convén asinalar un fenómeno de carácter fonético que afecta o encontro dunha vogal final - $a$ (ou da realización [j] da conxunción copulativa) en contacto coas formas de un: a vogal velar aberta de on, onha provén da contracción de /a/ e /u/, fenómeno típico da fala popular. Significativamente, Curros vai mudando o seu modelo lingüístico, sendo máis frecuente en Aires da miña terra, é apenas perceptíbel en $O$ divino sainete (só dous casos, un deles no manuscrito autógrafo, despois correxido na $1^{\mathrm{a}}$ edición). Os casos documentados aparecen 
sempre despois das preposicións a, contra e pra, e das conxuncións coma e $i$ (neste caso por disimilación entre fechadas): escribir nada mais pr'onha provincia, C 1.42; y-on carro... ¿y-a de vosté?, C 3.172; roxa com'on caravel..., C 3.173. O único caso dubidoso (decía onha vella, C 3.173) é explicábel por fonética sintáctica, pola presenza do - $a$ final de decía. Por outra parte, aínda se debe indicar a presenza, en diferente proporción, de formas vulgarizadas procedentes do castelán nadie acarón da forma correcta ninguén: nadia, naide e nadie. Nadia está presente en trece ocasións, ninguén en doce, e nadie en catro: que naide s'entende alí, C 3.234; naide as endrómenas ten, C 21.9; naide baila, C 21.24; como naide se vexa, $\mathrm{C}$ 27.4. A forma nadie só se rexistra unha única vez: de nadie recordos malos, PS 17.142.

No necesariamente complexo capítulo referido ao verbo destacaremos só aqueles aspectos que consideramos máis significativos pola súa importancia. As segundas persoas do plural das tres conxugacións apresentan tanto a conservación do $-d$ - da terminación como a desaparición da consoante e mais a posterior asimilación e crase vocálica, sendo este un trazo típico da área fisterrá usado frecuentemente por Rosalía de Castro; talvez Curros se vise influído pola poeta padronesa, pois esta desinencia é allea á zona lingüística de Celanova: que chamás progreso, C 2.8; de que lei / querés, C 25.40; cando chegués á cima, C 28.35; cantos amés, C 36.3; as soidades sentís d'os patrios eidos, PS 3.2; cando cruzás, PS 18.91; mais ao seu lado aparece: os que, cal eu, subides, C 28.33; q'inda pensades, C 32.33; cumprides, PS 3.125. Polo contrario, nas formas de imperativo Curros vacila entre a solución galega xeral (paráde, C 2.9; correde o velo, C 25.45; rachade, DS 0.95; Ladrade, mordede, ride, DS 0.97; remendade, PS 12.3) e a forma dialectal de procedencia, neste caso sen a crase fisterrá, excepto, loxicamente, na terceira conxugación: facéy montería, C 10.23; Romeiros, acudí!..., C 17.9; templáina, C 23.42; preguntáylle, C 25.17; dáille traballo, C 25.46; deixáino, C 25.57; mirayno, C 35.44; penduray, PS 14.190.

Por outra banda, a respeito das P4 e P5 do copretérito, antepretérito e pospretérito, debemos ter en conta o desprazamento acentual da vogal do sufixo modo-temporal á vogal temática nas P4 e P5: dábamos comenzo, DS III.2; tínamos, DS III.5; marchábamos, DS VI.142; non debérades tornar, PS 15.20. Ao seu carón topamos casos de mantimento do acento etimolóxico, inclusive, algúns deles, marcados con til polo proprio autor: rezabámos, C 9.46; viviámos, PS 10.88. Esta alternancia pode explicarse pola existencia dun territorio sen desprazamento acentual, próximo a Celanova, onde tamén existe unha pequena illa con formas analóxicas.

No apartado referido ao pretérito, centrarémonos, en primeiro lugar, nas solucións de P2, en que se produce vacilación entre os resultados etimolóxico (-che) e analóxico (-ches). Temos rexistrada 38 veces a primeira forma (chegache, DS I.103; xurache, DS I.105; recolliche, DS IV.124; levantache, DS IV.129; etc.), 
frente a 30 casos da segunda: se pagaches, DS VI.63; mandaches, PS 17.57. Ademais, en consonancia coa área xeográfica do autor, a vogal temática etimolóxica da P2 dos pretéritos fracos da $2^{\text {a }}$ conxugación é sempre /i/: naciches $t i$, C 24.8; mereciches, C 31.104; ti apareciche entón, C 34.9; metiche, DS V.163.

Polo que respeita a o sufixo número-persoal de P5 do pretérito, continúa a mesma vacilación, neste caso entre a forma hipercaracterizada -stedes (dixéstedes, C 32.21; nombrástedes, PS 3.7; puxéstedeslle, PS 3.11; soñástedes, PS 3.159) e a etimolóxica -stes: que á morte condenastes, C 25.39; recordastes, DS V.14; pensastes, PS 3.164.

Outra cuestión importante, con consecuencias sintácticas, é a presenza de usos de antepretérito no canto de pretérito de subxuntivo, en consonancia con usos populares: e pódia que certo fora, C 2.90; s'en sorte me tocara, C 2.608; cal si tiveran rebor, C 3.66; por mal que che fose, C 31.114.

Débese salientar, así mesmo, o magnífico dominio da lingua por parte de Curros no referente ao uso xeral e constante do futuro de subxuntivo. Os exemplos son abundantes: que quen quixere, C 2.99; conta non deres, C 2.516; vos fordes de paseo, C 2.1178; si pudér, C 25.40; si chegar á morrer, C 25.28; mais se non che bastar, C 31.143; cóntame o que vires, C 36.24; canto for meu, DS VIII.205; quen quixer, PS 3.176; a quen non nacer gallego, PS 14.244.

Finalmente, para alén do alto grau de uso do infinitivo flexionado (pra n'outono casárense, C 2.193; ó saberes tal notiza, C 33.55; seres dono, C 33.57; pra c'o libro te fagueres, C 33.61)", na obra de Manuel Curros Enríquez aparece frecuentemente o xerundio reforzado coa preposición en ou ende para indicar que a acción expresada por aquel é anterior á do verbo principal: a festa en chegando, C 29.8; que un ben topache en morrendo, DS II.23; persentóuse n'o recinto / un home, en berrando: "Nego o meu sufraxo á ese herexe..., DS II.76; ende lle dando ós pés. Aliás, en liña coa enxebreza manifestada na súa produción literaria, o poeta apresenta un alto uso das formas reducidas de certos participios acarón das formas regulares: nacidas, C 2.1; esta lámpara acendida, C 19.15; de pernas tortas, C 2.485; c'os ollos acesos, C 10.17; nádo n'os montes, C 14.29; están enxoitos, C 32.30; comesta d'os lobos / comesta morreu, PS 7.11-12.

Para rematar co capítulo referido a o verbo, ímonos deter en certas particularidades referentes á conxugación de verbos concretos, nomeadamente dalgúns semirregulares e irregulares. En primeiro lugar, débese indicar a presenza de formas analóxicas na conxugación do presente de indicativo de verbos con

\footnotetext{
Como corresponde á unha zona da provincia de Ourense en que se usan todas as formas do paradigma (García Gondar 1978: 22). É claro que, ás veces, a métrica impede a súa aparición: nóivos ó sair d'a misa, C 2.182; pr'estar com'o moucho / viñeche da sacha?, C 2.217.
} 
alternancia vocálica (que a Xusticia encubre, C 25.45; cando se cuspe, PS 14.145), mais sempre minoritarias en relación ás formas históricas: o peito sente, $\mathrm{C} 2.36$; que acod'a cita?, C 2.809; s'o conto non mente, C 15.34; e feren, C 15.38; sempre loce ben, C 31.164; soben ó pau as virtudes, PS 14.127; que cobre os osos, PS 14.266.

Así mesmo, no presente de indicativo dos verbos acabados en -aer, -oer, aparece frecuentemente a vogal temática fechada /i/ para a $3^{\mathrm{a}}$ persoa singular: cay $o$ Papado, C 17.11; dóise aquel d'un Sylock, C 29.68; trai, DS V.101; alí onde cai, DS VII.36; roi, PS 13.5; doy, PS 14.7; tray meus versos, PS 14.80.

Canto á conxugación de verbos irregulares, faremos unha esquemática revisión dalgúns especialmente significativos:

1. Dar. Este verbo mantén a solución deu na $3^{\mathrm{a}}$ persoa do pretérito en todos os casos que rexistramos (deull'á noiva, C 3.108; ;nay que me deu!, C 27.4; que nunca deu craridade, DS I.21; deulla, DS VII.61; deume un fillo, PS 3.27), cunha única excepción inducida pola rima, que provoca a aparición da forma analóxica dou no poema "A espiña", ao lado mesmo da forma histórica: deulle él sete á quen m'o dou, PS 14.84.

2. Dicir/decir. Curros, sendo fiel ao seu estilo, alterna constantemente tanto as formas decir e dicir (decirche esperaba, C 2.302; com'antes che decía, C 2.465; decindo, C 2.707; dicíndolle, C 15.91; decindo entre dentes, C 15.202; decía miña nay, C 25.3; volveu dicirme Gabriel, C 36.49), como as diversas solucións para a P2, P3 e P6 do Presente de Indicativo: tí dícelo, C 2.264; din a nay y-a madriña, C 29.11 .

3. Facer/Faguer. O poeta, natural da parte occidental de Ourense, segue en moitos casos o uso dialectal típico desta zona. No tema de presente a distribución do radical facer é maioritario nas falas galegas, rexistrándose a presenza de faguer na metade occidental da provincia ourensá. No tema de pretérito fix-é o radical maioritario, mais nesta zona ourensá aparece figu-. Como podemos observar nos exemplos que seguen, o noso autor utilizou máis frecuentemente as formas proprias do seu territorio lingüístico do que as outras: él pra faguer as vendimas, C 2.58; s'algunha ves o faguía, C 2.136; eu nada che figuen, C 2.253; d'o que figo, C 2.428; pra tal faguer, C 2.763; pra facer n'éla morada, C 2.880; Martiño fígos'o zorro, C 2.1113; mandey faguer testamento, C 21.55; pra faguer niño, C 22.16; fígome a figa, C 27.7; faguedes, C 31.21; en que figo ó machado mil pirmores, C 31.41; pra c'o libro te fagueres, C 33.61 .

4. Ouvir/Oír. En principio, as solucións no radical que o verbo ouvir pode apresentar nas formas arrizotónicas do tema de presente (excepto o subxuntivo) e de pretérito son ouv[-ir], ou[-ir], ougu[-ir], ademais de $o$ [-ir]. Nas obras do 
noso poeta todas e cada unha destas posibilidades son documentadas ${ }^{12}$ : cando teñades esta vos ouido, C 2.25; non sey cómo t'oyo, C 2.229 e 231; ouía gromas e cántigas, C 2.986; ouíunos o confesor, C 3.108; qu'era o qu'había qu'ouir, C 3.208; o son d'a gaita ouindo, C 4.53; vay oir, C 7.4; sin ouir seus amargos lamentos, C 11.23; y-on sapo q'o oía, C 14.11; s'ouíras os sermós, C 21.141; ninguén ouíu, C 28.13; o dia que m'as oyan, C 28.16; oyo á chamarme, C 31.76; y-ouvide a miña vos, C 36.4. Tamén podemos ver o substantivo deverbal: Non teño ouido xordo, C 2.822; chegóull'ó ouido, C 2.1066.

5. Pór/poñer. O verbo pór (e os seus compostos) é característico da provincia de Ourense, como testemuña Fernández Rei (1991: 98-99 e 134) ao estudar a súa distribución xeográfica: "No tema de presente teñen diferente distribución as formas pór, pomos, pondes (podes), puña, porei, poría... características de Zamora, case todo Ourense, a metade sur de Pontevedra e puntos esporádicos da Coruña e Lugo; poer, poemos, poeis, poía, poerei, poería... de falas asturianas; e poñer, poñemos, poñedes, poñía, poñerei, poñería... do resto do galego". En Curros as dúas formas alternan o seu uso: repoñéndose, C 2.625; quíxose pôr, C 2.701; en compoñerse, C 3.81; compuñan unha armunía, C 3.207; vay póndos'o sol, C 14.2; poñeino ante esta lámpara acendida, C 19.15; non me fagas porche preito, C 21.150; poñendo os meus fillos, C 29.51; aquí vos ven: disponde, PS 3.121 .

6. Querer. A conxugación deste verbo segue no noso autor a norma xeral, a excepción dalgunhas formas moi concretas da $2^{\mathrm{a}}$ e $3^{\mathrm{a}}$ persoas do presente de indicativo, en que alternan, respectivamente, queres/ques e quer/quere, á parte de queredes/querés (véxase supra), con aparición de formas típicas do occidente coruñés; afirma Fernández Rei (1991: 99): "No presente de indicativo deste verbo é relevante a distribución de quères, forma maioritaria [...] e quès, forma contracta característica do occidente da Coruña, ás veces en concorrencia con quères. Igualmente o é a distribución de quère, que é o xeral, frente á forma apocopada quèr, cunha área compacta no occidente da Coruña e outra no galego de Asturias e do Bierzo". Vexamos algunha exemplificación: falarme quere, C 2.806; que quer que lle levanten, C 2.815; que quer, C 2.816; si Dios quere, C 2.947; o mesmo quer o concello, C 2.949; e cand'a que tanto quere, C 2.1114; com'o qu'a cousa non quer, C 3.168; tanto te quer, C 21.59; que quere creer, DS I.114; cántigas quèr de galans, PS 5.4; d'aquelo que quer gozar, PS 5.16; quer que vos diga, PS 14.69; non quere o río, PS 15.21.

7. Saír/Salir. O estudo da lingua currosiana mostra a convivencia da forma saír, maioritaria, con algún caso de salir: saleu de apaseo, C 15.13; non sallo, PS 14.70 e 122. Outros exemplos son: dispois de saír, C 2.68; e d'aquí sán pr'os

12 Ademais dunha forma analóxica ouce: xa s'ouce o pío alegre, C 5.17. 
teares, C 2.119; saían, C 2.142; unha d'a boca lle say, C 2.323; saíu tranquilo xá, C 2.636; e Bras ó turreiro say, C 3.18; pol-a troneira say, C 16.20; ¿Qué cousas m'oxe sán, C 16.40; e pol-a posta que say, C 21.3; pra c'oa teima me sair, C 21.116; hastra que d'ela sayan, C 23.43; say d'ese altar, C 31.130 e 132; sayámos xa, C 31.170; d'a Grecia say Roma, PS 10.96; saín, PS 14.186.

8. Traer/Traguer. Neste verbo é significativa a presenza de formas que mostran unha conxugación dependente da minoritaria forma traguer, convivendo con resultados de traer: que trás contigo o frío, C 2.356; tráiche consolo e favor, $\mathrm{C}$ 2.414; trayo, C 9.7; que tray a boa nova, C 28.20; meus fillos vos trayo, C 29.34; vés traguer, C 29.46; meus nenos che trayo, C 29.54; ¿Trouguen as ágoas á Cruña?, PS 17.13 .

9. Ter. Canto a este verbo, merecen comentario algúns aspectos referidos á súa conxugación. En primeiro lugar convén destacar o comportamento que o poeta celanovés lle dá á $3^{a}$ persoa plural do presente de indicativo. Máis unha vez, Fernández Rei (1991: 101) infórmanos de que na P6 se rexistra tein na parte oriental da Galiza e tèn no oeste da Coruña, sul de Pontevedra e Ourense, constatando, ademais, que a forma tèn soe aparecer frecuentemente en concorrencia coa analóxica, e maioritaria, tènen. A variedade das solucións na obra do autor pódese apreciar nos exemplos que seguen: pr'a min tên frores, $\mathrm{C}$ 9.32; eses nomes tén virtude, C 33.115; que ten a pasión por guía, DS VI.57; tén as mesmas rodas, PS 10.58; que os teen tan gañados, PS 17.34; nin cult'os héroes tên, PS 19.40. Mais tamén se rexistra teñen: no teñen albergue, C 15.148; teñen a pátrea, C 31.137; teñen, PS 14.192.

Por outra banda, nos tempos de pretérito documéntase a alternancia das raíces tiv-/tuv, mostrando a interferencia do castelán na segunda forma: tiven un fillo d'achego, $\mathrm{C}$ 21.139; tivo tratos c'o demo, C 24.7; que xa tiven, C 29.24; tuvo, PS 11.53.

No ámbito da morfoloxía, fican aínda algunhas observacións sobre diversos adverbios, preposicións e conxuncións. A respeito do adverbio, salientamos a presenza das diversas series dos adverbios de lugar absolutos, aparecendo maioritariamente os da serie en -í: uns 35 casos de aquí (á parte da variante eiquí), 17 de aí e 23 de alí. Segue a serie en -á con un caso de acá (pr'acá d'o Pirene, PS 10.23) e 24 de alá. Na serie en -ó non documentamos acó, frente a dous rexistros de aló: aló n'o fondo, C 31.75 e aló n'o abril primeiro, 31.109. Finalmente, acolá recollémolo tamén dúas veces: acolá enriba, C 2.1161 e d'aquí pr'acolá, PS 10.12. Nos da serie en - $i$, Curros alterou as grafías na edición de Aires a respeito da $1^{\mathrm{a}}$ de "A Virxe do Cristal" en El Heraldo Gallego, pois neste aparecían as formas palatalizadas que o poeta modificou en 1880: elí, HG 2.67 e 2.73; eiqui, HG 1.123 (alí e aquí nas tres edicións de Aires); alí, C 2.67 e 73 (frente a elí en HG nos mesmos versos); aquí, C 2.118, 119, 121 e 124 (frente a eiquí en HG); etc. 
Tamén no ámbito adverbial se debe sinalar a presenza esporádica dunha asimilación consonántica no encontro do adverbio de negación non seguido do pronome persoal me (eu no me acordo, C 2.821), así como a crase deste mesmo adverbio con forma verbal iniciada por vogal, fenómeno popular tamén minoritario na obra de Curros, aproveitado con fins métricos, o mesmo que outros poetas contemporáneos: n'hay zapateiros, C 2.115; noxado n'estabas, C 2.220; un chau que n'é d'éles, C 15.118; n'hay quen non venda monte e devesa, PS 2.35; tal acasión n'aproveita, DS 0.87; ¿n'éverdade?, DS II.4.

Canto ás preposicións, existen diversas formas e usos na obra do poeta ourensán que merecen comentario. Así, é posíbel documentar en Curros certa vacilación verbo do uso da preposición $a$ con C.D., aínda que a interpretacións dalgunhas grafías resulta dubidosa: o servicio d'o rey chama ós mociños, PS 3.79 vs. y-os gallegos doma, PS 10.99 .

A forma do adverbio de lugar diante é empregada con valor prepositivo equivalente á locución diante de en varias ocasións: diante eles, PS 10.31; diante nos, PS 10.93; diante o trono e diante o altar, PS 11.25.

Por outra parte, dependendo por veces de factores métricos, a preposición para pode apresentar a forma reducida pra, que resulta maioritaria: para engordar, C 27.24; para n'éla vender, C 35.48; para a coba, DS II.41; para atallar a corrente, DS V.40; para facerme calar, PS 14.16 vs. pr'a que quen s'astreva, C 2.94; quedaban pra si dicindo, C 2.151; nacido pra azoute, C 29.43; pra dirixir, PS 3.17.

Tamén existe vacilación na elección entre desde e dende, con predominio desta última, xa que só localizamos unha vez a primeira forma: desde enton iqué tristeza en vos hay, C 11.28. Mais esta preposición convive coa locución déndes de ou déndesde ${ }^{13}$ : déndesd'a vila hastr'a aldea, C 2.192; déndesd'o ceo, C 2.419; mirada déndes de lonxe, C 2.653; Déndesd'o Lerez lixeiro, C 4.1; déndesd'esa aventura, DS II.100.

No relativo á conxunción condicional se predomina -sobre todo en Aires - a forma castelanizada $s i$, combinada coa forma reducida por crase, aínda que en $O$ divino sainete e nos poemas soltos a vacilación é maior, aparecendo comunmente se; o mesmo sucedía nos poemas "A Virxe do Cristal", "Unha voda en Einibó" e "O gueiteiro" publicados en El Heraldo Gallego, en que se manifestaba máis abertamente a presenza da forma se: e se canto ése morto... perdonaime, HG 2.48. Porén, si está presente no orixinal autógrafo de $O$ divino sainete, mais na $1^{\text {a }}$ edición (1888) aparece se.

13 Para un máis amplo estudo desta forma, véxase Ferreiro (1999: 214 e 361) e García de Diego (1984: 152-153). 
Con relación ás partículas comparativas ca/que e coma/como, débese sinalar que, en certas ocasións, na poesía de Curros aparece o pronome na súa forma recta precedido da forma como (de toparte como eu, C 31.88; todos como eu apenados, DS I.77). Dun modo semellante, pode aparecer que perante a forma ti como segundo termo da comparación: outros van máis emporcados / que tí, DS V 55-56.

\section{Léxico}

Por último, na análise da lingua de Curros debemos ter presente que o noso poeta é un dos autores do Rexurdimento que mostra un léxico máis rico e variado, sen dúbida pola amplitude da súa cultura e formación, reflectida en artigos de prensa como comentador literario, e mais pola grande cantidade de leituras que tiña feito. Desta forma, elabora literariamente un idioma que parte dunha linguaxe con marcado acento popular, matizando o seu léxico con abundantes cultismos froito do profundo coñecimento do mundo clásico. Mais, como todo escritor desta época, foi tamén escravo da situación lingüística que neses momentos se vivía, pagando o tributo de numerosas interferencias e/ou deformacións fonético-lexicais que en nengún momento restan interese e calidade á súa produción.

Neste sentido, Curros tampouco foi alleo á avasaladora influencia da lingua oficial, rexistrándose castelanismos sistemáticos na súa obra, como o substantivo Dios, introducido xa había ben tempo no idioma, e o adxectivo hermoso e os seus derivados; neste caso convén destacar que a súa presenza se dá maioritariamente en "A Virxe do Cristal", decaíndo o seu emprego ao irmos avanzando cronoloxicamente na edición da súa poesía (hermosa vida, C 2.361; unha rapaza hermosa, C 2.546; d'unha non vista hermosura, DS 0.90). Así mesmo, o xentilicio gallego é forma única, pois haberá que esperar ás Irmandades da Fala para que se faga efectiva a recuperación da forma lexítima. Hai, aínda, outra serie de palabras españolas que aparecen en contadas ocasións. Así, por exemplo, reina figura unha única vez (Reina d'hermosura, C 2.78); castellana (C 33.42); griego (d'os grandes tráxicos griegos, DS I.102; o vello sudario griego, DS IV.140); pulpo (PS 3.62); etc.

Outras veces aparecen pseudogaleguismos, constituídos por formas híbridas entre o galego e o español: ánxele, C 2.637; anx'liños, C 4.75; os Evanxelios, DS 0.20; lexos, PS 3.66; almexas, PS 4.5; Miguel Anxele, DS IV.150. Resulta, neste sentido, sorprendente a modificación da forma correcta galega gargallada que aparece no manuscrito autógrafo polo híbrido carcaxada en DS I.165, castelanismo facilmente evitábel.

Finalmente, existen palabras que alternan as súas formas entre a voz galega e a española. Por exemplo: y-a limosna, C 2.104, frente a a esmola, PS 3.176. 
Por outra banda, ao contrario do que acontece con, por exemplo, Pondal ou, despois, Noriega Varela, documéntanse na obra de Curros numerosos hipergaleguismos, arrastrado, sen dúbida, polo seu desexo de afastamento do castelán, que o leva a nivelar analoxicamente elementos de procedencia culta, a vocalizar grupos consonánticos en latinismos recentes, etc.: cencia, C 2.2; primaveira, C 5.6; estranas, C 13.33; mediciña, C 13.38; brilar, C 14.38, extranos, C 27.17; mediciña, C 29.27; montana, C 30.2; hourizonte, DS I.73; brilante, DS V.126; etc. Algunhas destas formas son exclusivas, en canto que outras apresentan tamén a forma correcta (brillou, C 2.613, frente á anterior brilar).

Finalmente, canto á formación de palabras, cabe pór en relevo na obra de Manuel Curros Enríquez dous procedimentos utilizados con alta frecuencia, cal a derivación sufixal e a composición. No ámbito da primeira salientaremos unicamente a utilización dos sufixos diminutivos, en especial o sufixo -iño. Os valores que apresentan as palabras con el formadas son variados, indo desde o indicador de tamaño ao intensificador de afectividade, pasando por todos os demais. Unha boa proporción deles acumúlase nos poemas apresentados ao Certame de Ourense, cheos dun significativo contido tradicional e costumista e moi próximos á fala popular. En C rexistramos máis dunha centena de exemplos: tan piquiniña, 2.819; ovelliñas 2.830; o coitadiño, 2.985; un ramiño, 2.994; caraveliño, 3.29; rapaciños, 6.9; meu queridiño, 7.47; branca pombiña, 9.26; filliña, 16.6; papeliños, 21.62; estreliñas, 22.24; santiño, 29.13; saniños, 29.61. En DS contabilizamos 12 casos: o tempiño foxe, 0.34 ; certos poetiñas, IV.54; xentiña, IV.82; e nos poemas soltos vimos 22: fontiña, HG 1.1; q'esas pestanas longuiñas, HG 1.9; pouquiño á pouco, PS 3.171. Algunhas veces, a palabra aparece reforzada pola acumulación nela de dous ou máis sufixos (Paráde un pouquichiñ'o fatigoso I paso, C 2.9; tan piquirriquichiño, C 2.792.

O resto dos diminutivos non chega a ter a presenza deste, e algúns deles apresentan outras connotacións, como o valor despectivo ou, mesmo, conforman palabras xa totalmente lexicalizadas: -ello (cortello, C 2.832); -etel-a (foguetes C 4.45, palleta, C 4.89); -ote (capote, DS I.7); etc.

Canto á tipoloxía compositiva que se rexistra na poesía currosiana, salientamos non tanto a súa abundancia como a criatividade dalgúns compostos, con elementos de variada condición: gardas fronteiros, C 16.53; católica-romana, C 31.27; críticaVeuillot, C 34.5; garda-fronteiro, DS VII.60; somellóume un peso-duro, DS VII.132; a virtude-vaca, PS 3.95; boi-deseo, PS 3.96; himno-titán, PS 3.201; mestre-canto, PS $17.120^{14}$. Non é un tipo de substantivos que abunden demasiado na súa obra, mais, dos que existen, as combinacións estruturais son variadas.

\footnotetext{
It Resulta curiosa a presenza de carros matos en PS 2.19, en que a flexión de número afecta os dous membros.
} 


\section{A modo de conclusións}

En Curros dáse un feito evidente que non ten parangón con nengún outro escritor da época: o seu alto dominio da lingua e a súa riqueza e variedade vocabular, unidos á intención de superar en todo o momento a fase inicial do idioma, fuxindo na medida do posíbel de vulgarismos innecesarios e de dialectalismos proprios da súa zona, tratando de lle dar a este unha unidade que naquel momento non posuía. Para iso, aínda que baseado na fala popular, seguiu aspectos da Gramática de Saco Arce sen deixar de sentir a influencia doutros autores coetáneos, especialmente de Rosalía. Percébese unha marcada evolución desde os poemas premiados no Certame de Ourense e publicados en El Heraldo Gallego até os seguintes da primeira edición de Aires da miña terra. En $O$ divino sainete a ansia de perfección levouno, mesmo, a pedir algunha rectificación ao editor Martínez Salazar, como vimos.

No tocante á grafía, mantivo decote un mesmo sistema con moi poucas diferenzas. A excepción vémola nos tres poemas do Certame de Ourense, que apresentaban unha serie de marcas gráficas, que despois o autor iría eliminando, como a excesiva presenza de apóstrofos por elisión de vogais.

Do ponto de vista fonético, reproduce a fala habitual daquel momento, cos correspondentes casos de alteracións de timbre vocálico, as metáteses consonánticas, a redución e vocalización de grupos cultos, as asimilacións e disimilacións e outros fenómenos típicos da lingua oral, sen que se poda rexistrar en nengún caso a gheada, xeral no seu territorio nativo.

No ámbito morfosintáctico, o galego literario de Curros caracterízase polo polimorfismo, xeral na súa época. Así acontece, por exemplo, na solución de -ANU/A, na formación do plural, con solucións características doutras áreas lingüísticas, ou na adscrición xenérica de diversos substantivos. É salientábel, ademais, a alta frecuencia de futuros de subxuntivo e de infinitivos flexionados, típicos do idioma.

No nivel léxico-semántico a riqueza e variedade do seu vocabulario é a característica máis salientábel. O dominio é tan absoluto que conviven con total naturalidade palabras de procedencia culta ao lado das expresións máis típicas e populares. Os hiperenxebrismos, castelanismos e vulgarismos marcan tanto os seus versos que hoxe posuímos un perfeito retrato do estado do idioma naquel período finisecular. Neste ámbito, de novo, hai unha grande diferenza entre os tres poemas premiados en Ourense e aqueles que representan o verdadeiro Curros reivindicativo e denunciante das inxustizas sociais. O primeiro é un léxico máis popular, máis enxebre; o segundo está adaptado aos temas que trata: é un léxico máis culto, con presenza dun elevado número de nomes proprios que fan referencia a personaxes históricas, literarias, políticas, relixiosas, etc. 
Curros, que cría na súa lingua, tratou sempre de a dignificar e elevala á categoría das outras que a rodeaban. A súa posición canto ao idioma tiña de ser a posición dun verdadeiro fillo da Galiza amante do país. Loitou pola dignificación e o progreso da nosa terra e iso levou aparellada a loita pola dignificación do idioma. As súas ideas de home formado e maduro reflectíronse no seu desexo de fundar unha Academia para sistematizar e unificar a lingua, pois decatábase claramente dos perigos de desaparición e de dialectalización que esta corría. O seu desexo, irreal, era convertela na lingua universal de todos os humanos, como puxo de manifesto no primeiro poema do libro Aires da miña terra. Hoxe as letras galegas aínda se laian da desaparición prematura deste home que tratou de marcar un máis alá para a Galiza, lonxe de todo populismo folclórico e perto da realidade lingüística, social, económica e política que a caracterizaban.

\section{Referencias bibliográficas}

A: Aires d'a miña terra, Ourense, Tipografía de A. Otero Editor, 1880 [Primeira edición].

Álvarez, R. / Regueira, X.L. / Monteagudo, H. (1986): Gramática galega (Vigo: Galaxia).

B: Aires d'a miña terra, Madrid, La Ilustración Gallega y Asturiana, 1881 [Segunda edición].

C: Aires d'a miña terra, A Coruña, Latorre y Martínez Editores, 1886 [Terceira edición].

Carballo Calero, R. (1972): Particularidades morfológicas del lenguaje de Rosalía de Castro (Santiago de Compostela: Universidade de Santiago de Compostela).

DS: O divino sainete, A Coruña, Imprenta La Comercial, 1888.

Fernández Rei, F. (1991): Dialectoloxía da lingua galega (Vigo: Xerais).

Ferreiro, M. (1999 [1995]): Gramática histórica galega (Santiago de Compostela: Laiovento).

Freixeiro Mato, X. R. (1993): Da montaña o corazón (Lugo: Fundación Caixa Galicia).

García de Diego, V. (1984): Elementos de Gramática Histórica Gallega. (FonéticaMorfología) 1909 [Edición facsimilar] (Verba, Anexo 23: Universidade de Santiago de Compostela).

G[arcía] Gondar, F. (1978): O infinitivo conxugado en galego. Anejo 13 de Verba (Santiago de Compostela: Universidade de Santiago de Compostela).

López Varela, E. (1998): A poesía galega de M. Curros Enríquez. Tomo 1 (A Coruña: Deputación Provincial da Coruña). 
López Varela, E. (2000): "O posicionamento de Curros perante a lingua", Revista Galega de Filoloxía, 1: 199-208.

Martínez-Morás Soria, A. (1987): “Testemuño dunha amizade. Curros Enríquez e Martínez Salazar”, A Nosa Terra. Extra n 9: 22-24.

Saco Arce, J. A. (1868): Gramática Gallega (Lugo: Imprenta de Soto Freire). 